\title{
Examining Attitudes of Students Regarding the Sports Education Model and Direct Teaching Model
}

\author{
Nevruz Bilgin ${ }^{1}$, Oğuzhan Dalkıran ${ }^{2}$ \\ ${ }^{1}$ The Ministry of National Education, Afyonkarahisar, Turkey \\ ${ }^{2}$ School of Physical Education and Sports, Mehmet Akif Ersoy University, Burdur, Turkey \\ Correspondence: Oğuzhan Dalkıran, School of Physical Education and Sports, Mehmet Akif Ersoy University, Burdur, \\ Turkey.
}

Received: October 22, 2017

Accepted: November 19, 2017 Online Published: November 21, 2017

doi:10.11114/jets.v5i12.2718

URL: https://doi.org/10.11114/jets.v5i12.2718

\begin{abstract}
The aim of the research was to investigate the effects of sports education model and direct teaching model on the attitudes of the students, and the differences among the attitudes of students. The study group of the research included 29 students from $6^{\text {th }}$ and $7^{\text {th }}$ grade of a secondary school in the 2015-2016 academic years. The experimental group consisted of students attended in the sixth class in which the physical education and sports lesson was conducted using the "sports education model" while the control group was the students in the 7th class in which the physical education and sports lesson was conducted using the "direct teaching model". As a data collection tool; the "Internal Motivation Inventory" developed by Ryan (1982) and adapted to Turkish by Çalışkur (2013) was used. In the analysis of the data; the "Mann Whitney U" test was used for the significance of the differences between post-implementation attitudes of the groups. In addition, the interview questions prepared by the researchers were answered by the students and the data were recorded. As a result; significant differences were found in the students' interest/enjoyment, perceived competence, value/benefit, effort/importance and work perception dimensions, but no significant difference was detected in the perceived choice rights and pressure/tension.
\end{abstract}

Keywords: affective domain, direct teaching model, physical education and sports teaching, sports education model

\section{Introduction}

According to the contemporary concept of education, an individual is the person who uses the knowledge s/he has gained in order to gain new knowledge, comprehends the events deeply, thinks in a critical manner, makes use of reasoning, uses and develops the cognitive skills such as scientific thinking and problem solving (Orbeyi \& Güven, 2008). Under the conditions where repeating the knowledge is meaningless for the individual, constructivist approach, which helps for the transformation of the knowledge and the reconstruction thereof, is becoming widespread in every stage of the education programs in many countries (Sert, 2008). The changes experienced in education manifest themselves in today's sports education and teaching program, as well. Every country strives to guide the human types it will raise and the education policy, develop and change the same in accordance with the necessities of the time. For this purpose, it is absolutely necessary to develop and change the teaching programs (Kaptan \& Kuşakçı, 2002).

Teacher-centered direct teaching model is also referred to as open expression and active teaching. This model is the teaching method that requires a regular program and to be systematic in the use of tools, aims to provide the mastership of the student in particular skills and provides high-level participation (Güzel, 1998). Lack of motivation experienced by the students in physical education lessons, starting a higher education before providing basic skills at an adequate level, not comprehending the game forms in an adequate level and not reflecting the same to the sports background, domination of the skilled students in the groups and the students being unable to find the suitable learning environment have reinforced the pursuit of new model (Çelen, 2012).

According to the constructivist approach, knowledge is constructed and produced by the learner. For this reason, knowledge is specific to the person. Constructivist approach argues that the student should be active in the learning environment (Özmen, 2004). A radical change was made in the physical education program in our country in 2006; it was aimed to contribute to the physical, cognitive, emotional and social development of the individual and provide his/her lifetime participation in physical activities. Realization of the constructivist approach in physical education 
lessons can be proportional to the active participation of the student in the process and the reflection of what s/he has learned to the real life in line with the student centeredness and active participation principles (Turkish Republic Ministry of Education [MEB], 2009). In accordance with these purposes, the aim of sports education model is to raise knowledgeable, skilled and willing sports people.

Few studies are encountered in literature with respect to "raising knowledgeable sports people", which is one of the aims of sports curriculum. While some of these studies indicate that sports education model provides the increase of knowledge (Ormond et al., 2002; Browne et al., 2004; Hastie \& Curtner-Smith, 2006; Hastie \& Sinelnikov, 2006; Mohr et al., 2006), some studies have emphasized that sports education model does not have any positive effect on the increase of knowledge (Pritchard et al., 2008). It can be said that looking at studies as a whole, the findings obtained are mostly positive. However, in some cases practice of sports education creates difficulty. For example; in the study by Hastie (1998), girl students stated that boy students establish dominance during the competitions and unfair situations occur while applying for some non-player roles. Moreover, in a study applying sports education model, it is determined that some of the students evade responsibility and do not collaborate with the other members of their team (Brunton, 2003).

As will be understood from the name of this model, thanks to the physical education and sports and extracurricular activities, students are enabled to learn sports by living and also learn personal and social responsibility concepts while learning sports-related skills and information. Thus, physical education and sports not only provide physical benefits but social benefits, as well. Accordingly, the aim of this research is to determine whether sports education model and direct teaching model used in physical education and sports lessons create a difference among the attitudes of the students.

\section{Method}

\subsection{Research Model}

In the study, experimental research model, in which cause and effect relations between the variables are examined and the results are taken quantitatively and transferred concretely, was used. The data in this study were limited to data obtained from 6th and 7th grade female and male students. The results of this study are important in point of determining how selected teaching models influence students' attitudes.

\subsection{Study Group}

Control group of the study is composed of a total of 11 secondary school 7th grade students as 4 girls and 7 boys while the experiment group is composed of a total of 18 secondary school 6th grade students as 7 girls and 11 boys, and the study group consists of 29 secondary school students in total.

\subsection{Data Collection Process}

While 6th-grade students studying in a public school constitute the experiment group, 7th-grade students constitute the control group. Physical education lessons were taught using sports education model for 12 weeks with the experiment group. In the first four-week process, basic information-skills about the outlines of the model and the badminton branch selected. In the second four-week process, the teams were formed and distribution of tasks was made and the groups made planning by themselves and the studies were started. In the last four-week process, however, preparation tournament and practices of celebration were included. With the control group, on the other hand, physical education lessons were taught using the direct teaching model for 12 weeks. At the end of the 12-week process, 'Intrinsic Motivation Inventory' was applied to the experiment and control group students. Experimental group students were provided with the tasks of coaching, refereeing, health representative, press representative, and composition committee membership. After the practice, experiment group students were asked the prepared interview questions about the model applied, the answers were recorded and evaluated by 3 domain experts.

\subsection{Data Collection Tools}

In the study, in order to collect data "Intrinsic Motivation Inventory", which was developed by Ryan (1982), the validity and reliability of which was tested by Çalışkur (2013) and which was adapted to Turkish, was used. The inventory consists of 32 attitude sentences. These expressions were prepared according to the 7-Likert scale starting from "never true", "sometimes true" to "usually true" expressions. In the inventory, "being interested/enjoyment", perceived competence", "perceived option", "value/benefit", "effort/importance", "work perception", "pressure/tension" dimensions are included. Score calculation is as much as the score value presented in rating for the plain expressions in the inventory (for example, if 1 it is 1 , if 7 it is 7 ) In the inventory, the expressions 3, 4, 13, 15, 18, 20, 23, 24, 26 are on the contrary. The scores corresponding to these expressions are transformed into a new score through subtraction from 8. As another data collection technique, interview method and qualitative data collection technique by way of recording the data were used. 


\subsection{Data Analysis}

Descriptive statistical analysis for data analysis and "Mann Whitney U" test due to the data not having a normal distribution for the significance of the difference between the attitudes of the groups after the practice were used. In the qualitative data analysis, common expressions detected by 3 branch teachers from the voice records were used. In the analyses made, the significance level was accepted as 0.05 .

\section{Findings}

When the transmissions of the students learning physical education and sports lessons with sports education model regarding the non-player tasks are evaluated, all students stated that they enjoyed the non-player tasks, each student mentioned the tasks s/he likes according to his/her interest while some students said that these tasks became the occupation that they would like to do in the future. Based on the answers given to the interview questions, it can be said that apart from being a player, the most important role attracting the interest of the students is coaching. Experimental group students stated that they learned how to respect and be thoughtful by empathizing through taking on different tasks and these tasks brought them in the skill of responsibility.

Table 1. Mann-Whitney U Test Results of the Being Interested/Enjoyment Dimension According to the Method Applied

\begin{tabular}{lccccc}
\hline Being Interested & $\mathrm{N}$ & Mean Rank & Rank Sum & $\mathrm{U}$ & $\mathrm{p}$ \\
Enjoyment & 18 & 19.61 & 353.00 & 16.00 & $.001 *$ \\
\hline Experiment Group & 11 & 7.45 & 82.00 & 16.00 \\
\hline Control Group & & &
\end{tabular}

*p $<0.05$

It is determined that there was a significant difference between the groups according to being interested/enjoyment dimension attitudes of the experiment group and control group students towards the physical education lessons $(\mathrm{U}=16.00$; $\mathrm{p}<.05$ ). Considering the mean ranks, level of being interested/enjoyment of the experiment group (Mean rank=19.61) is higher than the control group (Mean rank=7.45). According to this result, it can be said that sports education model affects the level of being interested/enjoyment more positively than the direct teaching model.

Table 2. Mann-Whitney U Test Results of the Perceived Competence Dimension According to the Method Applied

\begin{tabular}{llllll}
\hline $\begin{array}{l}\text { Perceived } \\
\text { Competence }\end{array}$ & $\mathrm{N}$ & Mean Rank & Rank Sum & $\mathrm{U}$ & $\mathrm{p}$ \\
\hline Experiment Group & 18 & 19.33 & 348.00 \\
Control Group & 11 & 7.91 & 87.00 & 21.00 & $.001 *$ \\
\hline
\end{tabular}

*p $<0.05$

It is determined that there was a significant difference between the groups according to perceived competence attitudes of the experiment group and control group students towards the physical education lessons $(U=21.00 ; \mathrm{p}<.05)$. Considering the mean ranks, level of perceived competence of the experiment group (Mean rank=19.33) is higher than the control group (Mean rank=7.91). According to this result, it can be said that students' ability to see themselves competent and have self-confidence is affected more positively in the sports education model than the direct teaching model.

Table 3. Mann-Whitney U Test Results of the Perceived Option Dimension According to the Method Applied

\begin{tabular}{llcccc}
\hline Perceived Option & $\mathrm{N}$ & Mean Rank & Rank Sum & $\mathrm{U}$ & $\mathrm{p}$ \\
\hline Experiment Group & 18 & 12.72 & 229.00 & \multirow{2}{*}{58.00} & \multirow{2}{*}{061} \\
Control Group & 11 & 18.73 & 206.00 & & \\
\hline
\end{tabular}

$\mathrm{p}>0,05$

It is determined that there was not any significant difference between the groups according to perceived option attitudes of the experiment group and control group students towards the physical education lessons (U=58.0; $p>.05)$. Considering that the articles in relation to the factor in the inventory are related to whether the activity chosen is performed voluntarily or not, it can be said that teacher attitude is a factor in not detecting any difference between the groups.

Table 4. Mann-Whitney U Test Results of the Value/Benefit Dimension According to the Method Applied

\begin{tabular}{llcccc}
\hline Value/Benefit & $\mathrm{N}$ & Mean Rank & Rank Sum & $\mathrm{U}$ & $\mathrm{p}$ \\
\hline Experiment Group & 18 & 19.36 & 348.50 & \multirow{2}{*}{20.50} & \multirow{2}{*}{$001^{*}$} \\
Control Group & 11 & 7.86 & 86.50 & & \\
\hline
\end{tabular}

$* \mathrm{p}<0.05$

It is determined that there was a significant difference between the groups according to the value/benefit dimension attitudes of the experiment group and control group students towards the physical education lessons $(U=20.50 ; p<.05)$. Considering the mean ranks, value/benefit level of the experiment group (Mean rank=19.36) is higher than the control 
group (Mean rank=7.86). According to this result, it can be said that sports education model affects the necessity of the subject and the availability thereof more positively than the direct teaching model.

Table 5. Mann-Whitney U Test Results of the Effort/Importance Dimension According to the Method Applied

\begin{tabular}{clcccc}
\hline Effort/Importance & $\mathrm{N}$ & Mean Rank & Rank Sum & $\mathrm{U}$ & $\mathrm{p}$ \\
\hline Experiment Group & 18 & 19.33 & 348.00 & \multirow{2}{*}{21.00} & $.001 *$ \\
Control Group & 11 & 7.91 & 87.00 & & .000 \\
\hline
\end{tabular}

$* \mathrm{p}<0.05$

It is determined that there was a significant difference between the groups according to effort/importance dimension attitudes of the experiment group and control group students towards the physical education lessons $(\mathrm{U}=21.00$; $\mathrm{p}<.05)$. Considering the mean ranks, level of effort/importance of the experiment group (Mean rank=19.33) is higher than the control group (Mean rank=7.91). According to this result, it can be said that sports education model affects the students' level of making effort and being good more positively than the direct teaching model.

Table 6. Mann-Whitney U Test Results of the Work Perception Dimension According to the Method Applied

\begin{tabular}{clllll}
\hline Work Perception & $\mathrm{N}$ & Mean Rank & Rank Sum & $\mathrm{U}$ & $\mathrm{p}$ \\
\hline Experiment Group & 18 & 12.36 & 222.50 & \multirow{2}{*}{51.50} & \multirow{2}{*}{$.031 *$} \\
Control Group & 11 & 19.32 & 212.50 & & \\
\hline
\end{tabular}

$* \mathrm{p}<0.05$

It is determined that there was a significant difference between the groups according to the work perception dimension attitudes of the experiment group and control group students towards the physical education lessons $(\mathrm{U}=51.50 ; \mathrm{p}<.05)$. Considering the mean ranks, work perception level of the experiment group (Mean rank=12.36) is lower than the control group (Mean rank=19.32). According to this result, considering that the articles included in the work perception dimension have common meanings such as boringness of the activity, not arousing interest and inability to perform the skill of movement, the fact that the control group has higher averages in this factor can be associated with the fact that it has more negative attitude than the experiment group.

Table 7. Mann-Whitney U Test Results of the Pressure/Tension Dimension According to the Method Applied

\begin{tabular}{llllcc}
\hline Pressure/Tension & $\mathrm{N}$ & Mean Rank & Rank Sum & $\mathrm{U}$ & $\mathrm{p}$ \\
\hline Experiment Group & 18 & 16.08 & 289.50 & \multirow{2}{*}{79.50} & \multirow{2}{*}{.375} \\
Control Group & 11 & 13.23 & 145.50 & & \\
\hline
\end{tabular}

$\mathrm{p}>0,05$

There was not any significant difference between the groups according to the pressure/tension dimension attitudes of the experiment group and control group students towards physical education lessons $(U=79.50 ; p>.05)$. Considering that the articles in relation to the factor in the inventory are related to the pressure the students feel in lessons, it can be said that teacher attitude has an effect.

\section{Discussion and Conclusion}

All experiment group students stated that they are aware of the responsibilities of the different roles they have taken; besides they are informed of the tasks they have taken on and these roles will considerably affect their choice of profession in the future.

Çelen (2012) and Koyuncuoğlu (2015) in similar studies determined that the opinions about the model applied are positive and mostly positive answers are given to the expressions such as working in harmony as a team, making common decisions, cooperation, responsibility, establishing good relations of friendship, confidence, respect and tolerance development, motivation, making effort, being patient, appreciating, creating a group identity and acquiring rich sports experiences. As a result of the study made by Perlman (2012), it is determined that the participation in the lessons made using sports education model increased the opportunity of providing the students having low motivation with higher physical activity levels.

According to the research result, it is found that the sports education model affected the level of being interested/enjoyment more positively than the direct teaching model. As a similar result, Wallhead and Ntoumanis (2004), in their study on high school students, found that there was an increase in the students' level of enjoyment the lesson made with sports education model while there was not a significant increase in the students' level of enjoyment the lesson made with direct teaching model. In addition, MacPhail et al. (2004) applied sports education model in the 5 th-grade students and detected that the model was more attractive to students than traditional approaches, as a result of the union of the departments with team loyalty such as official competitions and festivals.

According to the research results, it is determined that in the sports education model the ability of the students to see 
themselves competent and feel more confident was affected more positively and that the necessity of the subject and the availability according to the value/benefit dimension attitudes were positively affected and that the level of making effort and being good according to the effort/importance dimension attitudes were positively affected. Considering that the articles included in the work perception dimension have common meanings such as boringness of the activity, not arousing interest and inability to perform the skill of movement, the fact that the control group has higher averages in this factor is associated with the fact that it has a more negative attitude than the experiment group. In a similar study, Koyuncuoğlu (2015) obtained statistically significant differences in favor of the sports education model in all the skills between the gain levels of forward roll, backward roll, headstand roll, hoop and cartwheel skills constituting the psychomotor skills of the students having gymnastics lessons with sports education model and direct teaching model. Although both models are effective in learning skills, it is stated that the sports education model is more effective than the direct teaching model in students' learning and development of gymnastic skills.

With regards to the effect of the sport education model on the affective domain; MacPhail et al. (2004), Schneider and Marriott (2010), Sinelnikov \& Hastie (2010) found in the studies with students from different age groups that attitude to and interest in the lesson developed more positively compared to the direct teaching model.

In the research, the fact that there was not any significant difference between the groups in terms of the perceived choice dimension and the pressure/tension dimension can be derived from the attitude towards the teacher entering the lesson.

As a result, sports education model considerably increased the students' interest in, participation in and attitudes towards the lesson. The different roles undertaken in the model provided positive developments of students in different dimensions, and therefore they stated that they would like to have next physical education lessons with this model. By making a good planning about each topic in the physical education lessons, it is possible to have fun in the lessons and actively participate in the lessons by acquiring individual responsibilities using sports education model.

\section{Acknowledgments}

This study was prepared by utilizing the master thesis made in Mehmet Akif Ersoy University Institute of Education Sciences and was supported by the Coordinator of Scientific Research Projects of Mehmet Akif Ersoy University.

\section{References}

Brunton, J. A. (2003). Changing hierarchies of power in physical education using sport education. European Physical Education Review, 9(3), 267-284. https://doi.org/10.1177/1356336X030093005

Çelen, A. (2012). The effect of volleyball lessons on the cognitive, emotional and psychomotor access levels of the students with the sport education model (Unpublished doctoral dissertation). Gazi University Educational Sciences Institute, Ankara.

Güzel, R. (1998). The effectiveness of the individualized reading comprehension material presented in the direct teaching method in the achievement of storytelling comprehension skills of the students in the lower special classes (Unpublished doctoral dissertation). Gazi University Social Sciences Institute, Ankara.

Hastie, P. A. (1998). Skill and tactical development during a sport education season. Research Quarterly for Exercise and Sport, 69(4), 368-379. https://doi.org/10.1080/02701367.1998.10607711

Hastie, P. A., \& Curtner-Smith, M. D. (2006). Influence of a hybrid sport education-games for understanding model on one teacher and his students. Physical Education and Sport Pedagogy, 11(01), 1-27. https://doi.org/10.1080/17408980500466813

Hastie, P. A., \& Sinelnikov, O. A. (2006). Russian students' participation in and perceptions of a season of sport education. European Physical Education Review, 12(2), 131-150. https://doi.org/10.1177/1356336X06065166

Kaptan, F., \& Kuşakç1, F. (2002, September). Effect on student creativity of brainstorm technique in science teaching. Paper presented at the 5th National Science and Mathematics Education Congress, Middle East Technical University, Ankara, Turkey. Abstract retrieved from http://old.fedu.metu.edu.tr/ufbmek-5/b_kitabi/PDF/Fen/Poster/t50d.pdf

Koyuncuoğlu, K. (2015). The effects of gymnastıcs courses with sport educatıon models on cognitıve, discrete and psychomotor access levels (Unpublished doctoral dissertation). Gazi University Educational Sciences Institute, Ankara.

MacPhail, A., Kirk, D., \& Kinchin, G. (2004). Sport education: promoting team affiliation through physical education. Journal of Teaching in Physical Education, 23, 106-122. https://doi.org/10.1123/jtpe.23.2.106

MEB (2009). General Directorate of Secondary Education, Secondary School Physical Education Course Curriculum: 
9th-12th Grades, Bursa: Turkish Republic Ministry of Education.

Mohr, D. J., Townsend, J. S., \& Pritchard, T. (2006). Rethinking middle school physical education: combining lifetime leisure activities and sport education to encourage physical activity. Physical Educator, 63(1), 18-29.

Orbeyi, S., \& Güven, B. (2008). Teachers' perceptions related to the evaluation component of the education program of primary school education mathematics studies. Journal of Theory and Practice in Education, 4(1), 133-147. http://eku.comu.edu.tr/index/4/1/sorbeyi_bguven.pdf

Özmen, H. (2004). Learning theories in science teaching and technology-aided constructivist learning. The Turkish Online Journal of Educational Technology, 3(1), 100-111. http://www.tojet.net/articles/v3i1/3114.pdf

Perlman, D. (2012). The influence of the sport education model on amotivated students' in-class physical activity. European Physical Education Review, 18, 335-345. https://doi.org/10.1177/1356336X12450795

Pritchard, T., Hawkins, A., Wiegand, R., \& Metzler, J. N. (2008). Effect of two instructional approaches on skill development, knowledge and game performance. Measurement in Physical Education and Exercise Science, 12(4), 219-236. https://doi.org/10.1080/10913670802349774

Ryan, R. M. (1982). Control and information in the intrapersonal sphere: An extension of cognitive evaluation theory. Journal of Personality and Social Psychology, 43, 450-461. https://doi.org/10.1037/0022-3514.43.3.450

Schneider, R. C., \& Marriott, S. T. (2010). Applying sports education model to basketball. Journal of Physical Education, Recreation \& Dance, 81(2).

Sert, N. (2008). Constructivism in the elementary school curricula. Journal of Theory and Practice in Education, 4(2), 291-316. http://eku.comu.edu.tr/index/4/2/nsert.pdf

Siedentop, D. (1994). Introduction to sport education. In D. Siedentop (Ed.), Sport education: Quality PE through positive sport experiences (pp. 3-16). Champaign, IL: Human Kinetics.

Sinelnikov, O. A., \& Hastie, P. A. (2010). Students' autobiographical memory of participation in multiple sport education seasons. Journal of Teaching in Physical Education, 29, 167-183. https://doi.org/10.1123/jtpe.29.2.167

Wallhead, T. L., \& Ntoumanis, N. (2004). Effects of a sport education intervention on students' motivational responses in physical education. Journal of Teaching in Physical Education, 23, 4-18. https://doi.org/10.1123/jtpe.23.1.4

\section{Copyrights}

Copyright for this article is retained by the author(s), with first publication rights granted to the journal.

This is an open-access article distributed under the terms and conditions of the Creative Commons Attribution license which permits unrestricted use, distribution, and reproduction in any medium, provided the original work is properly cited. 